\title{
Ensino de Meio Ambiente e Geociências em Escolas Técnicas Estaduais de São Paulo: Estudo de Caso nas ETEs de Iguape e Santo André
}

\author{
Arlei Benedito Macedo (abmacedo@usp.br) e Carolina Maia Cotrim \\ Departamento de Geologia Sedimentar e Ambiental - Instituto de Geociências - USP \\ R. do Lago 562, CEP 05508-080, São Paulo, SP, BRA
}

Recebido em 04 de fevereiro de 2005; aceito em 05 de agosto de 2005

Palavras-chave: Geociências, ensino técnico, Geologia, Iguape, Vale do Ribeira.

\section{RESUMO}

O Meio Ambiente tem adquirido uma importância cada vez maior para todas as comunidades do planeta, devido à percepção dos efeitos das ações humanas sobre a natureza. Esta importância resulta na necessidade de um ensino de boa qualidade das disciplinas de Geociências, em todos os níveis educacionais, tanto para o exercício consciente da cidadania quanto para atuação profissional nesse campo de conhecimento. Muitos cursos técnicos de nível médio do Estado de São Paulo oferecem disciplinas de Geociências; no entanto, muitas vezes as ementas dos cursos não são desenvolvidas por profissionais com conhecimento específico de Geociências. Um dos cursos com maior concentração de disciplinas de Geociências é o de Meio Ambiente, estudado neste trabalho. A partir do levantamento da situação atual do ensino das disciplinas de interesse, nas escolas do Centro Estadual de Educação Tecnológica Paula Souza, constatou-se que a soma de competências, que se declara desenvolver, é grande demais para que seja possível a capacitação de um Técnico em Meio Ambiente, dentro do tempo disponível para o curso, além de uma organização confusa das ementas relacionadas a algumas disciplinas, e da falta de condições para ensino e aprendizagem eficientes, não obstante o esforço de professores e funcionários. Recomenda-se um estudo rigoroso do currículo, no que se refere a competências e programas das disciplinas, elaboração de materiais didáticos, treinamento e fornecimento de condições para que as escolas possam exercer suas funções de ensino e extensão.

Keywords: Geoscience, technical schools, Geology, Iguape, Ribeira Valley.

\section{ABSTRACT}

The environment is assuming every day a greater importance for all communities of the planet, as a consequence of the perception of the effects of human actions on nature. This importance results in the need of good quality teaching of Geoscience subjects at all academic levels, in order to develop a conscious exercise of citizenship as well as to prepare for professional activity in this field. There are many high-school level technical courses in the State of São Paulo that offer Geoscience subjects in the curriculum, and in some courses these are core subjects. The contents of the subjects are sometimes not planned by people with professional training in Geosciences. One of the courses having a large Geoscience content is the Environmental Technician course. A survey of the present condition of the courses at the Paula Souza State Technological Education Center revealed that a great number of skills have to be developed in the available time for the course, that the subject contents are disorganized, and that there is a lack of conditions for efficient teaching and learning, in spite of the efforts of faculty and staff. A strict study of the curriculum as regards skills and subject programs is recommended, together with the preparation of teaching materials, teacher training programs, and the provision of adequate conditions to allow schools to fulfill their functions of teaching and extension. 


\section{INTRODUÇÃO}

O meio ambiente tem adquirido cada vez mais importância na sociedade, ainda que tardiamente, conseqüência da percepção dos impactos ambientais ligados ao grande desenvolvimento urbano e tecnológico, o que torna uma consciência ambiental imprescindível na formação de um cidadão. Esta importância também é refletida na necessidade de um ensino das disciplinas de Geociências de boa qualidade, em todos os níveis educacionais, tanto para o exercício consciente da cidadania quanto para uma atuação profissional nesse campo de conhecimento.

Não foram encontradas referências de trabalhos relacionados ao ensino de Geociências em cursos técnicos de nível médio no Brasil, o que torna este estudo necessário, ainda mais pelo fato das ementas das disciplinas desses cursos muitas vezes não terem sido desenvolvidas por profissionais com formação específica em Geologia.

A instituição onde foi desenvolvido este projeto é o Centro Estadual de Educação Tecnológica Paula Souza (CEETEPS), que mantém 99 Escolas Técnicas Estaduais (ETEs). As disciplinas relacionadas às Geociências são ministradas nos Cursos Técnicos de Edificações, Agricultura, Agrimensura, Meio Ambiente e Mineração.

Além de um estudo geral sobre as disciplinas de Geociências nas ETEs, duas delas foram visitadas: a ETE Júlio de Mesquita, no município de Santo André e a ETE Engenheiro Agrônomo Narciso de Medeiros, localizada no Município de Iguape. A pesquisa propriamente dita foi realizada para o trabalho de formatura de Carolina Maia Cotrim (Cotrim, 2001), no curso de Geologia do Instituto de Geociências da USP, orientado pelo primeiro autor, sendo compatibilizado com as atividades desenvolvidas por ele e por alunos de Geologia e Geografia da USP, nos projetos de "Apoio ao Ensino Técnico em Escolas Estaduais" e "Divulgação de Geociências", financiados pelo Fundo de Cultura e Extensão, pelo Instituto de Geociências e por uma bolsa do programa Bolsa Trabalho da USP, executados de 2001 a 2003.

\section{PROJETO DE PESQUISA}

O projeto teve como objetivo geral o levantamento da situação atual do ensino das disciplinas relacionadas às Geociências nos cursos técnicos de nível médio do Estado de São Paulo, e previa as seguintes atividades:

1. levantar as disciplinas de Geociências e respectivas ementas em todos os cursos;

2. verificar o andamento do ensino nos cursos, a partir de trabalhos conjuntos com as coordenações do Centro Estadual de Educação Tecnológica Paula Souza;

3. efetuar observações em escolas, abrangendo a ETE Engenheiro Agrônomo Narciso de Medeiros no Município de Iguape e a ETE Júlio de Mesquita, no município de Santo André.

Os objetivos foram apenas parcialmente atingidos na pesquisa relatada neste trabalho.

\section{FUNDAMENTAÇÃO BIBLIOGRÁFICA}

Não foram encontradas referências bibliográficas específicas sobre o ensino de Geociências nos cursos técnicos no Brasil. Foram examinados alguns estudos como Ramos (1997), que discute o histórico e as últimas mudanças ocorridas na legislação da educação técnica de nível médio, facilitando o entendimento da situação atual, incluindo uma visão dos alunos de cursos técnicos.

Também foram consultados trabalhos sobre ensino de Geociências, porém esses abrangiam níveis de ensino diferentes do abordado neste trabalho. Dentre os consultados destacam-se: Amaral (1981), discute o conteúdo e o enfoque dos livros de geologia introdutória; Negrão (1983), aborda a pesquisa e a metodologia de ensino na formação do geólogo; Compiani (1988), desenvolveu a questão do fazer geologia na formação de professores de Ciências para o ensino fundamental ( $1^{\mathrm{a}}$ a $5^{\mathrm{a}}$ séries $)$ e Lopes (1988), analisa a atuação educacional em museus de Geociências.

Foram também analisadas as ementas dos cursos técnicos de nível médio que incluem disciplinas de Geociências, nos programas do Centro Estadual de Educação Tecnológica Paula Souza (CEETPS) e nas diretrizes curriculares federais para os cursos técnicos, além de materiais e livros empregados, tais como "Tecnologia e Ambiente” (Morandi, 2000).

\section{TRABALHOS REALIZADOS}

Além da pesquisa bibliográfica, foram realizadas reuniões com os coordenadores de área (Professoras Raquel Fabbri Ramos - Meio Ambiente e Sônia Morandi-Turismo) e com o coordenador geral de ensino técnico do CEETEPS, obtendo-se uma idéia do funcionamento dos cursos, complementada pelo fornecimento dos programas e do resultado de uma pesquisa, realizada entre os prováveis empregadores, do perfil desejável dos técnicos de Meio Ambiente.

Foram também efetuadas visitas à ETE Engenheiro Agrônomo Narciso de Medeiros, em Iguape e à ETE Júlio de Mesquita, em Santo André, nas quais foram feitas 
observações sobre as condições materiais e pedagógicas, e feitas entrevistas estruturadas e não estruturadas, com alunos, professores, coordenadores e diretores.

\section{RESULTADOS OBTIDOS}

\section{O ensino técnico no Estado de São Paulo}

O quadro legal onde se encontra a educação profissional, hoje, é definido pela Lei de Diretrizes e Bases da Educação Nacional (LDB), $n^{\circ} 9.394 / 96$, onde se estabelece que a educação profissional tem como função levar ao "permanente desenvolvimento de aptidões para a vida produtiva”. O ensino técnico, por sua vez, tem seu perfil ligado ao ensino médio, admitindo o caráter complementar, ou seja, a educação profissional não substitui a educação básica, mas a complementa, podendo ser oferecida de forma concomitante ou seqüencial a esta.

O CEETEPS, encarregado das Escolas Técnicas Estaduais de São Paulo, oferece o ensino técnico, segundo a LDB (Lei $n^{\circ}$ 9.394/96 e Decreto $\left.n^{\circ} 2.208 / 97\right)$, da seguinte maneira: os cursos estão organizados em módulos, cada um com duração de um semestre, sendo cada habilitação composta por 2, 3, ou 4 módulos. Cada módulo cursado dá ao aluno uma qualificação profissional, com direito a um certificado. O conjunto de certificados dos módulos cursados e que formam uma habilitação profissional, dará direito ao diploma de técnico, desde que o aluno já tenha concluído o ensino médio. $\mathrm{O}$ ingresso nos cursos técnicos do CEETEPS se dá por meio de processo seletivo ("vestibulinho") para alunos que tenham concluído, no mínimo, a 1ª́rie do ensino médio.

As escolas técnicas mantidas pelo CEETEPS apresentam numerosas dificuldades financeiras e de infra-estrutura para o desenvolvimento de seus trabalhos, pagando salários muito baixos e oferecendo pouco incentivo à capacitação de seus professores. Os alunos, em muitos casos, apresentam formação geral deficiente, procurando compensar com o ensino técnico a impossibilidade do ingresso no ensino superior público.

\section{Programas dos cursos}

Conforme as diretrizes e programas do CEETEPS (1999, 2001), as disciplinas de Geociências são ministradas nos cursos técnicos de Meio Ambiente, Mineração, Agricultura, Edificações e Agrimensura, com cargas diferentes nos diversos cursos, como pode ser observado na Tabela 1. A duração desses cursos é de três semestres. No curso de formação de Técnico em Meio Ambiente, com a conclusão do primeiro módulo o estudante adquire a habilitação de Auxiliar de Preservação Ambiental, do segundo, Auxiliar de Técnico em Meio Ambiente e do terceiro, após cumprir o estágio supervisionado, recebe a habilitação de Técnico em Meio Ambiente.

Por esses dados verifica-se o pequeno número e a pouca abrangência das disciplinas de Geociências nos cursos analisados. Particularmente no curso de Meio Ambiente, aqui detalhado, os objetivos especificados para o $1^{\circ}$ Ciclo (60 h), são "Enunciar conceitos fundamentais relativos ao ciclo das águas” e "Descrever técnicas usadas em planimetria”; no $2^{\circ}$ ciclo (60 h), são "Descrever os processos internos e de formação da Terra" e "Enunciar conceitos básicos de Geologia” e no $3^{\circ}$ ciclo (100 h), "Descrever técnicas usadas em altimetria” e "Explicar o uso eficiente da cartografia como instrumento de identificação e representação de riscos naturais”. Assim sendo, a carga aparentemente alta sob o título de Geociências abrange na realidade 90 h de conteúdo de Geociências (Hidrologia e Geologia) e 130 h de Topografia e Cartografia (CEETEPS, 1999), tratando dos tópicos listados na Tabela 2.

Tabela 1. Carga horária das disciplinas de Geociências nos cursos técnicos do CEETEPS (horas-aula). (1) Embora com este nome, 2/3 da carga horária correspondem a Topografia e Cartografia. (2) Noções em "Agricultura Geral". (3) Noções em "Solos e Fundações". (4) Noções em "Irrigação e Drenagem". Fonte: grades horárias e ementas dos cursos do CEETEPS (1999 - 2002).

\begin{tabular}{lccccc}
\hline \multicolumn{1}{c}{ Disciplinas } & Meio Ambiente & Mineração & Agricultura & Edificações & Agrimensura \\
\hline Geociências & $220^{(1)}$ & - & - & - & - \\
Geologia & - & 160 & - & - & - \\
Solos & - & - & $10^{(2)}$ & $20^{(3)}$ & 40 \\
Materiais de Construção & - & - & - & -80 & - \\
Topografia & - & - & - & - & 320 \\
Hidrologia & - & 80 & - & - & 40 \\
Desenho Topográfico & - & 180 & - & - & 300 \\
Métodos de Pesquisa e Lavra & - & & & - \\
\hline
\end{tabular}


Para todos os cursos, o conhecimento da estrutura e funcionamento da Terra, em seus aspectos físicos, é essencial para o desempenho profissional. Esses assuntos são pouco ensinados no ensino fundamental e médio, além de que os alunos podem seguir o curso técnico concomitantemente ao médio. Isto leva a uma lacuna que deveria ser reparada no curso técnico. Observando as ementas detalhadas (CEETEPS, 1999), conclui-se que apenas o curso de Mineração apresenta noções de Geociências em extensão compatível com a formação esperada do técnico, compreendendo 220 h, estritamente de conteúdo geológico, na disciplina Geologia. As noções de Topografia e Cartografia são tratadas em disciplina específica, com uma carga de 160 h, além de mais 80 h em Desenho Topográfico.

Os conteúdos das disciplinas Geociências do curso de Meio Ambiente e os tópicos de Geologia do curso de Mineração são apresentados na Tabela 2.

\section{Curso de Técnico em Meio Ambiente}

O curso de Técnico em Meio Ambiente é oferecido nas ETEs de Campinas, Cruzeiro, Espírito Santo do Pinhal,
Iguape, Santo André e Jundiaí, sendo este o mais antigo, implantado há dois anos.

\section{Plano de Curso do CEETEPS}

A coordenação de Meio Ambiente do CEETEPS desenvolveu um plano de curso para a área, divulgado em janeiro de 2001, orientado por uma pesquisa realizada pelo Departamento de Pesquisas e Estudo Econômicos da FIESP/CIESP, em abril de 2000, com empresas e profissionais, procurando avaliar as necessidades e expectativas dos empresários com relação à implementação de cursos específicos para as áreas que exigem sistemas de controle ambiental.

Foi enviado um questionário a 4.750 empresas, sendo que 936 responderam, e destas, 522 disseram necessitar de algum controle ambiental, o qual é realizado em $61,3 \%$ delas por um departamento específico ou por funcionários habilitados em questões ambientais, recorrendo o restante a consultoria especializada.

As principais áreas de interesse das empresas são a gestão e o controle ambiental, necessitando de capacitação dos seus profissionais no tratamento de resíduos líquidos (38,7\%),

Tabela 2. Tópicos de Geociências tratados nos cursos de Mineração e Geociências do CEETEPS. Fonte: programa do curso de Mineração (CEETEPS, 1999) e ementas do curso de Meio Ambiente (CEETEPS, 2002).

\section{Disciplina}

Geologia, curso de Mineração (160 h) Há também disciplinas de Topografia (160 h), Desenho Topográfico $(80 \mathrm{~h})$ e Métodos de Pesquisa e Lavra (180 h)

\section{Tópicos}

Minerais e rochas. Caracterizar e classificar os principais tipos de minerais e rochas. Identificar e correlacionar ambientes geológicos com depósitos minerais. Forma dos corpos mineralizados. Classificação das jazidas. Controle das mineralizações. Características físicas da Terra. Identificar estruturas geológicas planares e lineares. Interpretar mapas e perfis topográficos e geológicos. Identificar as técnicas de mapeamento. Perfis geológicos e topográficos. Dinâmica interna da Terra. Dinâmica externa da Terra. Geologia ambiental.

$1^{\circ}$ Ciclo. Ciclo hidrológico. Bacia hidrográfica. Precipitação. Infiltração. Evaporação. Escoamento superficial. Regime dos cursos d'água e represamento. Previsão de enchentes. Transportes de sedimentos. Conceitos de: Topografia, Planimetria e Altimetria. Unidades de medida: lineares e angulares. Áreas de figuras regulares e irregulares. Planimetria: amarrações à terra e teodolito, trabalho com coordenadas.

Geociências, curso de Meio Ambiente Notar que inclui $2 / 3$ de noções de Topografia e Cartografia, que não dispõem de disciplinas próprias $2^{\circ}$ Ciclo. Formação da Terra. Constituição e processos internos. Escala geológica do tempo. Noções de mineralogia, petrologia e petrografia. Geotectônica. Noções de geomorfologia e pedologia. Geologia econômica.

$3^{\circ}$ Ciclo. Altimetria: referências de cotas/altitudes, medida de diferenças de nível de terrenos, métodos de nivelamento. Curvas de Nível: interpretação e traçado, plantas planialtimétricas, declividades e perfis e longitudinais. Interpretação dos tipos de mapas. Símbolos convencionais. Representação topográfica. Projeções. Fotografia aérea e sensoriamento remoto. Sistema brasileiro de cartografia. Aplicação da cartografia como instrumento de identificação e representação de riscos naturais. 
poluição sonora (34,5\%) e descarte de resíduos sólidos (30,3\%). Há, também, uma tendência de aumento dos investimentos em tecnologias destinadas à redução de resíduos.

A questão da preservação de áreas verdes também foi abordada no plano de curso, tendo em vista que o Estado de São Paulo possui 900 mil hectares de floresta tropical, e que a ETE de Iguape se insere na região que concentra os maiores remanescentes dessa floresta, cuja alta biodiversidade necessita ser protegida.

Em conformidade com a pesquisa e com a organização geral dos cursos do CEETEPS, o curso Técnico de Meio Ambiente é organizado em 3 módulos. Pretende-se que a cada módulo sejam adquiridas qualificações parciais, detalhadas em culminando nas atribuições e responsabilidades do técnico, quais sejam, conforme CEETEPS (2001):

O Técnico em Meio Ambiente atua na área industrial, agrícola, florestal, em órgãos governamentais voltados à questão ambiental, desenvolvendo atividades que objetivam a educação e a preservação ambiental, auxiliando na gestão ambiental e em procedimentos de:

a. identificar, caracterizar e correlacionar os sistemas e ecossistemas, os elementos que os compõem e suas respectivas funções;

b. identificar e caracterizar as grandezas envolvidas nos processos naturais de conservação, utilizando os métodos e sistemas de unidades de medida e ordens de grandeza;

c. identificar os parâmetros de qualidade ambiental dos recursos naturais (solo, água, ar);

d. classificar os recursos naturais (água e solo) segundo seus usos, correlacionando as características físicas e químicas com sua produtividade;

e. identificar as fontes e o processo de degradação natural de origem química, geológica e biológica e as grandezas envolvidas nesses processos, utilizando métodos de medição e análise;

f. identificar características básicas de atividades de exploração de recursos naturais renováveis e não-renováveis que intervêm no meio ambiente;

g. identificar e caracterizar situações de risco e aplicar métodos de eliminação ou de redução de impactos ambientais;

h. identificar e correlacionar o conjunto dos aspectos sociais, econômicos, culturais e éticos envolvidos nas questões ambientais;

i. avaliar as causas e efeitos dos impactos ambientais globais na saúde, no ambiente e na economia;

j. identificar os processos de intervenção antrópica sobre o meio ambiente e as características das atividades produtivas geradoras de resíduos sólidos, efluentes líquidos e emissões atmosféricas;

l. avaliar os efeitos ambientais causados por resíduos sólidos, poluentes atmosféricos e efluentes líquidos, identifi- cando as conseqüências sobre a saúde humana e sobre a economia;

m. aplicar a legislação ambiental local, nacional e internacional;

n. identificar os procedimentos de avaliação, estudo e relatório de impacto ambiental (AIA/EIA/RIMA);

o. utilizar sistemas informatizados de gestão ambiental;

p. auxiliar na implementação de sistemas de gestão ambiental em organizações, segundo as normas técnicas em vigor (NBR/ISO 14001);

q. interpretar resultados analíticos referentes aos padrões de qualidade do solo, ar, água e da poluição visual e sonora, propondo medidas mitigadoras;

r. aplicar princípios e utilizar tecnologias de preservação e correção da poluição;

s. organizar e atuar em campanhas de mudanças, adaptações culturais e transformações de atitudes e condutas relativas ao meio ambiente.

O Técnico em Meio Ambiente possui as seguintes atribuições e responsabilidades, ainda conforme CEETEPS (2001):

a. compreender os grandes impactos ambientais globais e suas conseqüências do ponto de vista econômico;

b. conhecer os mecanismos de percepção e avaliação da significância dos impactos ambientais, domínio de técnicas e procedimentos gerenciais aplicáveis;

c. conhecer as técnicas, princípios e requisitos legais, procedimentos gerenciais envolvendo os recursos naturais (água, ar, solo);

d. identificar os procedimentos para a exploração racional dos recursos naturais;

e. leitura de mapas que permitam a formulação de diagnósticos, avaliação de alternativas em manejo ambiental;

f. interpretar fotografias aéreas e imagens de satélite meteorológico;

g. identificar sistemas gestores de áreas degradadas pelas intervenções antrópicas;

h. conhecer os mecanismos de AIA/EIA/RIMA e sua legislação prevista para o PCA, RCA, e PRAD;

i. conhecer e interpretar a Legislação Ambiental Brasileira e internacional de maior interesse (normas, atos, convenções);

j. elaborar projetos de uso sustentável dos recursos naturais, tais como agrícolas.

É notável a grande quantidade e complexidade das qualificações e competências esperadas dos educandos. Nesse ponto, as referências curriculares estaduais concordam quase literalmente com as federais (apresentadas em MEC, 2001). Essas qualificações devem ser adquiridas, conforme o plano de curso do CEETEPS (1999), cumprindo um programa com as características listadas na Tabela 3 seguinte: 
Tabela 3. Habilitação profissional de Técnico em Meio Ambiente. Fonte: CEETEPS (1999).

\begin{tabular}{|c|c|c|c|c|}
\hline \multirow{2}{*}{ Matérias e componentes curriculares } & \multicolumn{3}{|c|}{ Ciclos (módulos de 20 semanas) } & \multirow{2}{*}{$\begin{array}{l}\text { Carga horária total } \\
\text { (horas-aula) }\end{array}$} \\
\hline & $1^{\circ}$ & $2^{\circ}$ & $3^{\circ}$ & \\
\hline \multicolumn{5}{|l|}{ Organização e Normas } \\
\hline Gestão e Qualidade & - & - & 2 & 40 \\
\hline Higiene e Segurança no Trabalho & 2 & - & - & 40 \\
\hline \multicolumn{5}{|l|}{ Ciências Ambientais } \\
\hline Química do Meio Ambiente & 3 & 3 & - & 120 \\
\hline Ecologia e Recursos Naturais & 3 & 3 & - & 120 \\
\hline \multicolumn{5}{|l|}{ Elementos de Geologia } \\
\hline Geociências & 3 & 3 & 5 & 220 \\
\hline Microbiologia & 3 & - & - & 60 \\
\hline Saneamento Ambiental & 2 & 2 & 2 & 120 \\
\hline Sistema de Tratamento de Águas e Resíduos & - & 3 & 3 & 120 \\
\hline Hidrobiologia & - & 2 & - & 40 \\
\hline Tecnologia de Controle da Poluição & - & 3 & 3 & 120 \\
\hline \multicolumn{5}{|l|}{ Fundamentos e Processos Industriais } \\
\hline Tecnologia de Processos Industriais & - & 2 & 3 & 100 \\
\hline Desenho Técnico & 2 & - & - & 40 \\
\hline \multicolumn{5}{|l|}{ Planejamento e Avaliação Ambiental } \\
\hline Legislação Ambiental & - & - & 2 & 40 \\
\hline Gestão Ambiental, Conservação e Uso do Solo & - & 2 & - & 40 \\
\hline Avaliação de Riscos e Impacto Ambiental & - & - & 3 & 60 \\
\hline Informática & 3 & - & - & 60 \\
\hline Carga horária do mínimo profissionalizante & 21 & 23 & 23 & 1.340 \\
\hline \multicolumn{5}{|l|}{ Disciplinas optativas } \\
\hline Leitura e Produção de Textos & 2 & - & - & 40 \\
\hline Inglês Instrumental & - & 2 & - & 40 \\
\hline Estatística & - & - & 2 & 40 \\
\hline Carga horária das disciplinas optativas & 2 & 2 & 2 & 120 \\
\hline Carga horária dos conteúdos profissionalizantes & 23 & 25 & 25 & 1.460 \\
\hline Carga horária do estágio supervisionado & & & & 400 \\
\hline Carga horária total do curso & & & & 1.860 \\
\hline
\end{tabular}

\section{Outros cursos de Meio Ambiente no Brasil}

Procurou-se levantar informações sobre alguns cursos oferecidos em outras regiões do Brasil, para comparação com os das escolas estaduais. Conforme o Censo da Educação Profissional (MEC, 1999), o Brasil possui 86 cursos técnicos em Meio Ambiente, sendo que em 34 deles as questões do lixo, água e esgoto são enfatizadas, e em 52 cursos o enfoque maior é dado à reciclagem.

Como exemplos, podem ser apresentados os objetivos de dois cursos:

1. o curso técnico em Meio Ambiente do Colégio João Paulo I, localizado em Araucária - PR, foi desenvolvido em
1995, sendo o primeiro do Brasil em parceria com entidades públicas e privadas. A grade curricular foi montada com base em pesquisa realizada junto às empresas da Região Metropolitana de Curitiba. O objetivo desse curso é capacitar profissionais de nível médio para:

a. executar planos e programas de atividades de controle e prevenção da poluição;

b. efetuar levantamentos, organizar e manter cadastros de fontes de poluição;

c. programar e realizar coletas de amostras, exames de laboratório e análises de resultados para a avaliação da qualidade de um determinado ecossistema;

d. participar da elaboração de normas, especificações e 
instruções técnicas relativas ao controle de poluição ambiental e da preservação do Meio Ambiente;

e. efetuar levantamentos de fauna e flora em áreas de preservação e conservação ambiental;

f. atuar em programas de educação ambiental;

g. executar programas de preservação do Meio Ambiente;

h. participar de elaboração de relatórios de avaliação ambiental;

i. participar da elaboração de planos diretores urbanos e regionais.

2. o curso do Centro Federal de Educação Tecnológica (CEFET), de Goiás, tem como objetivo formar profissionais para trabalhos de impacto ambiental, capacitando-os quer para a prática de ações preventivas, como para o conhecimento e emprego de tecnologias corretivas, que visem à melhoria, à recuperação da qualidade ambiental e à preservação dos recursos naturais da vida no planeta (CEFET GO, 2001). O aluno deve apresentar e desenvolver:

a. interesse pela preservação do meio ambiente;

b. capacidade investigatória e busca de conhecimento;

c. facilidade de relacionamento e liderança;

d. perseverança e sociabilidade;

e. ter atitude ética.

Os cursos oferecido pelos CEFETs de Minas Gerais e do Rio Grande do Sul, possuem objetivos semelhantes aos de Goiás (CEFET - MG, 2001).

\section{Características das escolas estudadas}

\section{ETE Engenheiro Agrônomo Narciso de Medeiros, de Iguape}

O município de Iguape, localizado no sul do Estado de São Paulo, possui uma população de 27.410 habitantes (IBGE, 2001), com baixa renda, mantida principalmente por turismo e agricultura. Ele está inserido no Vale do Ribeira, o qual se situa na divisa dos estados de São Paulo e Paraná, contendo sua bacia de drenagem $26.310 \mathrm{~km}^{2}$, dos quais $17.180 \mathrm{~km}^{2} \mathrm{em}$ São Paulo e $9.130 \mathrm{~km}^{2}$ no Paraná. Devido à semelhança nas condições ambientais, podem ser acrescentadas à bacia propriamente dita as porções litorâneas próximas, do sul de São Paulo e nordeste do Paraná, perfazendo aproximadamente $40.000 \mathrm{~km}^{2}$, formando a região geográfica do Ribeira e Litoral. As características mais importantes da região são:

1. grande parte da área mantém as condições ambientais muito mais preservadas que no resto dos estados que a contêm, ressaltando-se extensos remanescentes da Mata Atlântica;
2. a porção litorânea da região abriga importantes áreas de reprodução de peixes;

3. a população da região, perfazendo 359.229 habitantes na porção paulista (IBGE, 2001) apresenta baixa renda e condições sociais precárias, resultando em baixo IDH para todos os municípios da área (Iguape tem 0,757, o que o faz sétimo da região, mas $492^{\circ}$ no Estado, conforme IPT/DEES, 2003).

O Vale do Ribeira, por ter uma extensa área ainda preservada de vegetação natural, teve aproximadamente metade de sua superfície abrangida sob Unidades de Conservação, decretadas a partir da década de 60. A economia regional, que até então era baseada na agricultura e extrativismo, passou por dificuldades, resultando em desemprego e migração para as áreas urbanas, sem a correspondente criação de empregos. A ETE Engenheiro Agrônomo Narciso de Medeiros, situada em Iguape, é a única escola técnica pública do Vale do Ribeira, sendo uma das menores e mais pobres do sistema CEETEPS. Ela funciona desde 1971 e, até o ano de 1998, possuía somente a habilitação de Técnico em Agropecuária, implantando-se, a partir de 1999, cursos de Meio Ambiente, Florestal e Turismo, sendo o de Agropecuária redefinido como de Agricultura, triplicando o número de alunos entre 1996 e 2002.

Em 2001 existiam 186 alunos matriculados, sendo 70 residentes na escola. Os cursos oferecidos eram: $3^{\circ}$ ano do ensino médio (26 alunos); $1^{\circ}$ módulo do curso Técnico de Florestal, (40 alunos); $2^{\circ}$ módulo de Técnico em Agricultura (29 alunos); $2^{\circ}$ (30 alunos) e $3^{\circ}$ (27 alunos) módulos de Técnico em Turismo; e $2^{\circ}$ módulo de Técnico em Meio Ambiente com 34 alunos matriculados. No ano de 2000, ocorreram 84,76\% de aprovação, $12,86 \%$ de reprovação, 2,38\% de transferência e 0\% de evasão. Existem na ETE 19 professores e um auxiliar de instrução, com professorescoordenadores de todos os cursos oferecidos (Plano Escolar - ETEEANM, 2001).

A partir das características da escola e da região, evidencia-se a necessidade de promover a melhoria das condições de vida da população, sem comprometer, porém, a riqueza ambiental ainda existente. A melhoria da Escola Técnica é uma importante condição para o melhor aproveitamento dos recursos da região, desenvolvendo pesquisa, ensino e aplicação de tecnologias apropriadas.

A escola procura a integração com outras instituições, fazendo parcerias formais e informais, como o convênio com o Instituto Nacional de Meteorologia, para montagem de uma Estação Climatológica operada pelos alunos e a construção, com a Fundação SOS Mata Atlântica, de um Viveiro de Mudas de Espécies Nativas. As Prefeituras Municipais de Cananéia, Iporanga, Eldorado e Iguape viabilizam a permanência de alunos carentes, oferecendo uma bolsa de manutenção de R \$ 40,00 por aluno, que é repassada à Coope- 
rativa-Escola da Unidade para a aquisição de alimentos, preparados na escola e fornecidos aos alunos internos. Na época da realização da pesquisa as condições dos alojamentos eram precárias, tendo sido muito melhoradas por reformas possibilitadas por verbas conseguidas pela diretora junto ao CEETEPS.

No trabalho aqui relatado foram desenvolvidas atividades relacionadas a três projetos de Extensão e Cultura da USP, coordenados pelo primeiro autor e financiados pelo Fundo de Cultura e Extensão e pelo Instituto de Geociências. Além do apoio direto à escola, com atividades didáticas para alunos, foram desenvolvidos, em colaboração com a Diretoria da ETE e com a coordenação do CEETEPS, propostas para um Centro de Tecnologia Ambiental do Vale do Ribeira e programas para cursos de formação de tecnólogos e de especialização em Gestão Ambiental. Os esforços para captação de recursos para viabilização dessas iniciativas continuam.

\section{ETE Júlio de Mesquita}

AETE Júlio de Mesquita, localizada em São André, região industrial do Estado de São Paulo, foi utilizada como referência de um curso técnico em Meio Ambiente, do CEETEPS, localizado em uma região com realidade diferente da ETEEA Narciso de Medeiros. O curso passou a ser oferecido no $2^{\circ}$ semestre de 2001, assim os alunos estavam freqüentando o $1^{\circ}$ módulo do curso quando entrevistados. Ao contrário da ETE Narciso de Medeiros, a de Santo André é uma escola com meios humanos e materiais suficientes, embora mantendo os problemas de baixos salários e poucos recursos de custeio.

\section{Pesquisa de campo}

Foram comparados os dois cursos de Meio Ambiente, por observações informais e questionários formais aplicados aos alunos.

\section{Observações informais}

Duas visitas foram realizadas à ETE de Iguape, diretamente relacionadas à pesquisa. Na primeira foram observadas as instalações da escola, além da apresentação do projeto para a Diretora; na segunda foram entrevistados três professores, aos quais foi aplicado um questionário com 14 perguntas abertas, e foram aplicados os questionários aos alunos.

A escola possui três salas de aula, que são usadas nos três períodos do dia. $\mathrm{O}$ ensino médio é oferecido durante a manhã e nos outros períodos são oferecidos os 4 cursos técnicos (Florestal, Meio Ambiente, Turismo e Agricultura).
Foram observados também o refeitório, o laboratório de informática, as acomodações dos alunos que moram na escola, o viveiro, a horta e as criações (porcos e coelhos). A biblioteca apresentou situação mais crítica entre as instalações da escola: os livros são poucos e em sua maioria desatualizados. A vontade e a determinação dos funcionários em tentar manter a escola em bom estado são claras, apesar das dificuldades financeiras.

Todos os três professores moram na região do Vale do Ribeira, e dois deles lecionam mais de uma disciplina na ETE. Os professores disseram estar sempre buscando a atualização dos assuntos abordados em aula, não só para a complementação do curso, mas também por interesse pessoal. Eles se mostraram dispostos a participar de cursos de capacitação e atualização. As dificuldades encontradas para o oferecimento das disciplinas são principalmente falta de material didático e de equipamentos técnicos e um nível baixo de conhecimento básico dos alunos.

Na ETE de Santo André foi realizada uma visita para apresentação dos objetivos da pesquisa ao diretor da escola e aplicação do questionário aos alunos. A biblioteca dessa ETE possuía uma quantidade muito maior de livros do que em Iguape, além de revistas e vídeos. No entanto, o material relacionado ao curso de Meio Ambiente era menor que na ETE de Iguape, correspondendo, como naquela, a uma única estante. Não foi estabelecido nenhum diálogo com alunos, nem com professores.

\section{Questionário formal: apresentação e aplicação}

A pesquisa foi realizada para a obtenção de um perfil característico dos alunos dos cursos técnicos de Meio Ambiente das duas instituições visitadas, tentando-se identificar a expectativa dos alunos com relação aos cursos e as perspectivas para o mercado de trabalho. $\mathrm{O}$ instrumento utilizado foi um questionário, com 53 questões fechadas, adaptado do Questionário do Perfil dos Estudantes de Graduação das IFES. Responderam ao questionário 28 alunos em Iguape e 23 em Santo André.

Os alunos são, em sua maioria, do sexo masculino, tanto em Santo André quanto em Iguape. A distribuição etária dos alunos é abrangente, sendo que em Iguape predominam alunos entre 20 e 25 anos, enquanto em Santo André alunos acima de 26 anos são predominantes, o que pode estar associado a reciclagem profissional. Isto é indicado também pelo fato que, dos 23 alunos entrevistados em Santo André, somente um cursava o ensino médio concomitantemente ao ensino técnico, sendo que 69,6\% desses alunos iniciaram, mas abandonaram, algum curso superior. O local de nascimento da maioria dos alunos, em ambos os grupos, é em municípios próximos das ETEs e não nas sedes delas (Iguape ou Santo André). 
Possivelmente devido à maior oferta de trabalho e à faixa etária mais elevada, 73,9\% dos alunos da ETE de Santo André exercem atividade remunerada independente da escola, diferente da situação de Iguape, onde pouco mais de $20 \%$ dos alunos desenvolvem alguma atividade que gere remuneração. Em Iguape, 50\% dos alunos que trabalham desenvolvem atividades em tempo parcial, ou eventuais, 30\% em tempo integral, sem carteira assinada, e 20\% com carteira assinada. Em Santo André o nível de atividade integral e de formalidade é maior, com apenas $10 \%$ em atividades eventuais, $23 \%$ em tempo integral sem carteira e $67 \%$ em tempo integral e emprego formal. A falta de recursos nas escolas resulta em que um pequeno número de alunos exerça atividade escolar remunerada: $7,2 \%$ em Iguape (em estágios no viveiro de mudas, que gera recursos administrados pela cooperativa da escola) e $0 \%$ em Santo André.

A carência dos alunos pode ser comprovada pelo principal motivo de escolha da escola: ensino gratuito. E os principais motivos pela opção do curso associam-se, em Iguape, à possibilidade de realização pessoal e, em Santo André, às adequações das aptidões pessoais. No caso de Iguape, devido à não existência de cursos superiores públicos na região à época da pesquisa, os cursos técnicos noturnos em alguns casos eram cursados pelos alunos de maior idade por falta de opção de formação.

Com relação às perspectivas futuras, a maioria dos alunos de ambas as escolas espera adquirir uma formação profissional voltada para o mercado de trabalho, pretendendo ainda conciliar estudo e trabalho, após a conclusão do curso.

Quanto às atividades extraclasse, os alunos de Iguape apresentaram maior número de respostas positivas que os de Santo André; eles também apresentaram maior participação em movimentos religiosos (32,1\% - 21,7\%), em atividades político-partidárias (14,3\% - 8,7\%), no movimento estudantil (17,9\% - 0\%), em sociedades científicas (14,2\% - 8,7\%) e em movimentos comunitários (28,6\% - 17,3\%), enquanto ambos os grupos mostram alta participação em movimentos ecológicos (42,8\% - 39,1\%). Os de Santo André só apresentam maiores percentagens de resposta nas atividades artístico-culturais, com 34,7\% contra $21,4 \%$ de Iguape. Isto reflete as diferenças regionais, com os de Iguape mostrando o perfil comum do vale do Ribeira, de maior participação nas reivindicações básicas, além da maior disponibilidade dos alunos, com menor proporção trabalhando em tempo integral.

Em relação a tópicos atualmente considerados imprescindíveis a um profissional, em Iguape os alunos possuem muito pouco conhecimento de língua inglesa e informática, sendo a situação em Santo André um pouco melhor em relação aos conhecimentos de informática, mas não de inglês.

\section{CONCLUSÕES}

As noções de Geociências oferecidas no curso técnico em Meio Ambiente são insuficientes para o que se espera dos formandos, o que se repete nos cursos técnicos de Agricultura, Edificações, e Agrimensura, sendo adequadas apenas no de Mineração. É necessário fazer uma reavaliação do currículo e das disciplinas, com definição mais rigorosa das ementas. Devem ser separados em disciplinas específicas, conteúdos que agora estão misturados, como os de tópicos de Geociências e de Topografia na disciplina Geociências para o curso de Meio Ambiente.

Tanto nas definições dos cursos do CEETEPS quanto nos das escolas federais, as atribuições profissionais e competências declaradas são impossíveis de desenvolver em cursos de três semestres, ainda mais se concomitantes ao curso médio.

O levantamento realizado com os alunos do curso técnico em Meio Ambiente, das ETEs de Iguape e Santo André, mostrou a discrepância entre realidades de vida dos alunos, reflexo das diferentes situações socio-econômicas dos municípios.

Em diversos aspectos ficou claro, como nos casos das diferentes faixas etárias predominantes em cada escola, que a proximidade de um grande centro urbano requer maiores especializações e conhecimentos (inglês, informática) como requisitos à entrada no mercado de trabalho. A opção por cursos técnicos pelos alunos da ETE de Santo André parece muito mais associada (com base nas faixas etárias e situação empregatícia) a uma necessidade de sobrevivência no mercado. No caso dos alunos da ETE de Iguape, a escolha por esses cursos técnicos sugere muito mais um anseio por conquistar uma profissão, do que uma necessidade da manutenção de uma posição no mercado de trabalho.

\section{CONSIDERAÇÕES GERAIS}

\section{Considerações sobre os programas dos cursos}

Uma característica é comum aos cursos federais e aos do CEETEPS, é a soma de atribuições e competências profissionais do Técnico em Meio Ambiente, cujo total é grande demais para que seja possível a capacitação de um técnico dentro do tempo disponível para o curso. Confrontando-se a lista de qualificações com os títulos das disciplinas e a carga horária, e, lembrando que os cursos são de meio período, nota-se que, mesmo em estabelecimentos com meios excelentes, seria impossível adquirir tantas qualificações em tão pouco tempo, mesmo para alunos que já tivessem concluído com excelente aproveitamento o curso médio, o que geralmente não acontece. 
Alguns dos tópicos têm uma profundidade que só poderia ser alcançada por um curso superior, além de invadir atribuições profissionais específicas. Por exemplo, a lista de atribuições de técnico, segundo o CEETEPS, inclui: "Elaborar projetos de uso sustentável dos recursos naturais, tais como agrícolas" e "Leitura de mapas que permitam a formulação de diagnósticos, avaliação de alternativas em manejo ambiental”, e o programa federal: "Programar e realizar coletas de amostras, exames de laboratório e análises de resultados para a avaliação da qualidade de um determinado ecossistema”. Essas atribuições invadem as dos engenheiros agrônomos e técnicos agrícolas, pelo menos, e exigem formação muito complexa.

\section{Considerações sobre as escolas visitadas}

É preciso efetuar um treinamento dos professores, abrangendo a elaboração e uso de materiais didáticos, principalmente para as disciplinas de capacitação para atuação profissional. Os professores devem ser estimulados a elaborar projetos, com a participação dos alunos, para pesquisa e execução de serviços. Nada disso funcionará se não houver melhores condições salariais e recursos materiais nas escolas.

As escolas precisam de um urgente reforço de recursos, principalmente a de Iguape. Nas condições atuais estes recursos são insuficientes para que elas possam exercer minimamente as funções de ensino e extensão. Quanto mais carente é a área em que se localiza a escola, maior é a importância de suas funções de inclusão social dos educandos e da difusão de conhecimentos e serviços científicos e tecnológicos. Embora não tenha sido feita uma pesquisa formal sobre os egressos dos cursos, depoimentos de alunos e professores mostram que, embora nem todos tenham conseguido empregos nas áreas em que se formaram, todos tiveram melhores possibilidades no mercado de trabalho. Também melhoraram suas condições para aprovação em vestibulares, resultado do maior tempo dedicado aos estudos, durante o curso técnico.

Duas propostas elaboradas em conjunto pelo primeiro autor e pela coordenação do CEETEPS, do Centro de Tecnologia Ambiental do Vale do Ribeira e de um Curso de Especialização em Meio Ambiente não se concretizaram, por ter o governo do Estado preferido abrir novas escolas do que melhorar as condições das existentes. Seria interessante retomar essas iniciativas, pois elas permitiriam dinamizar as atividades da ETEEA Narciso de Medeiros, e contribuir para melhor aplicar conhecimentos científicos para a conservação ambiental e melhoria das condições de vida da população do Vale do Ribeira.

\section{REFERÊNCIAS BIBLIOGRÁFICAS}

AMARAL, I. A. O conteúdo e o enfoque dos livros de geologia introdutória: estudo descritivo e analítico com base na macro-estrutura das obras atuais destinadas ao nível superior de ensino. 259 p. 1981. Dissertação (Mestrado) Instituto de Geociências, Universidade de São Paulo, São Paulo, 1981.

BRASIL. Ministério da Educação. Educação profissional: referenciais curriculares de educação profissional de nível técnico, área profissional meio ambiente. Brasília, 2000. 51 p. Disponível em: <http://portal.mec.gov.br/setec/ arquivos/pdf/meioambi.pdf>. Acesso em: 20 dez. 2001.

BRASIL. Censo de educação profissional: levantamento dos cursos técnicos em meio ambiente no Brasil. Brasília, 1999.

CENTROFEDERAL DE EDUCAÇÃO TECNOLÓGICA DE GOIÁS. Curso técnico em Meio Ambiente. Goiânia, s.d. Disponível em: <http://www.meioambiente.cefetgo.br>. Acesso em: 20 dez. 2001.

CENTROFEDERAL DE EDUCAÇÃO TECNOLÓGICA DE MINAS GERAIS. Curso técnico em Meio Ambiente. Belo Horizonte, s.d. Disponível em: <http://www.meioambiente. cefetmg.br>. Acesso em: 20 dez. 2001.

COLÉGIO JOÃo PAULO I. Curso técnico em Meio Ambiente. Araucária, PR, s.d. Disponível em: <http://www.joaopaulo1.com.br>. Acesso em: 20 dez. 2001.

COMPIANI, M. O fazer geologia com ênfase no campo na formação de professores de Ciências para o $1^{\circ} \mathrm{grau}$ (5ª a $8^{a}$ séries). 238 f. 1988. Dissertação (Mestrado) Faculdade de Educação, Universidade Estadual de Campinas, Campinas, 1988.

COTRIM, C. M. A situação do ensino de Geociências nos cursos técnicos de nível médio do Estado de São Paulo. 2001. 40 p. Trabalho de Conclusão de Curso (Graduação) Instituto de Geociências, Universidade de São Paulo, São Paulo, 2001.

IBGE. Disponível em: <http://www.ibge.gov.br/ibge/ default.php>. Acesso em: 20 dez. 2001.

INSTITUTO DE PESQUISAS TECNOLÓGICAS. DEES. Fórum São Paulo Governo Presente: Região do Vale do Ribeira. São Paulo, 2002.85 p.

LOPES, M. M. Museu: uma perspectiva de educação em 
geologia. 1988. 163 p. Dissertação (Mestrado) - Faculdade de Educação, Universidade Estadual de Campinas, Campinas, 1988.

MORANDI, S.; GIL, I. C. Tecnologia e ambiente. São Paulo: Copidart, 2000.172 p.

NEGRÃO, O. B. M. A pesquisa e a metodologia de ensino nas escolas superiores de graduação em geologia no país. 1983. 186 p. Dissertação (Mestrado) - Instituto de Geociências, Universidade de São Paulo, São Paulo, 1983.

SÃO PAULO (Estado). Centro Paula Souza. Plano de curso técnico em Meio Ambiente do Centro Estadual de Educação Tecnológica Paula Souza. São Paulo, 2001. Versão digital. $<$ http://www.ceeteps.br>.

SÃO PAULO (Estado). Resumo das ementas dos cursos de nível médio e técnico do Centro Estadual de Educação Tecnológica Paula Souza. São Paulo, 2000. Versão digital. $<$ http://www.ceeteps.br>.

SÃO PAULO (Estado). Plano de curso técnico em Mineração do Centro Estadual de Educação Tecnológica Paula Souza. São Paulo,1999. Versão digital. $<$ http://www.ceeteps.br>.

SILVA, M. E. R. A formação do técnico de nível médio: origens, uma visão de alunos e sinais de mudanças. 1997. 203 p. Dissertação (Mestrado) - Faculdade de Educação, Universidade de São Paulo, São Paulo, 1997. 